\title{
Pensar la alfabetización hoy. Algunas reflexiones y la mirada especializada del Dr. José Manuel Pérez Tornero
}

\author{
Mariana Perticará(1)
}

\section{Introducción}

El contexto mediático actual interpela al ámbito educativo para incorporar nuevas alfabetizaciones (fundamentalmente audiovisual y digital).

La alfabetización centrada en la lectoescritura que fuera impulsada por los Estados modernos funcionó durante mucho tiempo, casi dos siglos.

(1) Universidad Nacional del Litoral Universidad Nacional de Entre Ríos marianaperticara@gmail.com Se requieren hoy nuevas alfabetizaciones. En países como Argentina, la mayoría de los ciudadanos —en especial los niños y los jóvenes han accedido más de la mano del mercado que con ayuda de los gobiernos-. Es en esta materia imperiosa la necesidad de consolidar estrategias de inclusión digital en términos de políticas públicas —en la formación de docentes y estudiantes en los distintos niveles educativos.

Gran parte de los docentes formados en la cultura letrada se ve hoy fuertemente impactada por los cambios. Gran parte de sus preocupaciones pasan por cómo enseñar a aprender en los nuevos contextos, cómo liderar la formación en estas nuevas alfabetizaciones

Existen diversos condicionamientos, factores o dimensiones que median la incorporación y apropiación del lenguaje audiovisual y digital: cuestiones de edad, rasgos sociales y culturales, condiciones grupales o familiares, diferentes contextos de recepción.

En el trabajo «La evolución de la alfabetización», Pérez Tornero y Varis (2012) brindan elementos para pensar las condiciones históricas de los procesos de alfabetización. Utilizando el recurso de la periodización 
histórica caracterizan en su trabajo diferentes etapas considerando los siguientes períodos históricos: Antigüedad clásica y Edad Media; Renacimiento; Ilustración; Primera Revolución industrial; Segunda Revolución Industrial; sociedad de la información. Con relación al escenario actual, señalan que estamos frente a un cambio de paradigma, transitando el paso desde el paradigma de la comunicación de masas hacia el paradigma de la comunicación multimedia en el que «el elemento distintivo es la convergencia de los diferentes medios, su complementariedad y solapamiento». A continuación reproducimos el intercambio con el Dr. José Manuel Pérez Tornero.

\section{¿Estamos frente a un cambio de paradigma con relación a la educación en medios? iEn qué sentido?}

Creo que el cambio viene determinado fundamentalmente por la transformación del escenario tecnológico. La irrupción de las TIC ha supuesto un cambio radical. Al mismo tiempo la reconfiguración social que significa la globalización, los problemas de sostenibilidad y la nueva posibilidad de participación política introducen un contexto muy diferente al tradicional. El resto lo introduce la aceleración de la revolución científica y del conocimiento. Se ha acabado la educación en medios tradicionales. Hemos de iniciar un nuevo marco conceptual en el que los medios - todos ellos- son nuestro entorno vital próximo y, por tanto, cognitivo y educativo.
¿A qué se denomina alfabetización mediática e informacional? Según la UNESCO, la Unión Europea y algunos otros organismos internacionales y académicos, se trata de la adquisición de las competencias que nos permiten ser autónomos, críticos y socialmente activos en relación a nuestro entorno mediático y semiótico fruto de la actual revolución digital y comunicativa.

¿Es correcto considerar hoy de la necesidad de alfabetizaciones múltiples en diferentes lenguajes en los diferentes tramos del proceso educativo? ¿Por qué, en qué sentido?

Es absolutamente imprescindible. Los lenguajes y los medios nos proporcionan la obligada vía de acceso al conocimiento hoy en día. Por tanto o nos desenvolvemos bien en relación con ellos o sucumbimos. 
¿De qué manera debe encararse la alfabetización en los niveles educativos iniciales?

Cuando se aprende a hablar y a escribir, a dibujar, y hasta a expresare gestualmente, se están aprendiendo lenguajes, semióticas, escrituras... Y en todo ello intervienen medios y tecnologías. Por lo tanto, alfabetizarse es un proceso natural. Hacerlo conscientemente depende del proceso educativo y pedagógico. No es difícil tener en cuenta que tras cada aprendizaje encontraremos siempre un nuevo significado, un nuevo lenguaje y una nueva aproximación mediática al mundo.

¿Cuáles son las dimensiones en el uso de las TIC que deben tenerse en cuenta en la formación de los profesores?

Las TIC son, a la vez, instrumentos técnicos, lenguajes, prácticas e instituciones sociales. Introducirlas en la educación - y, por tanto, en la formación del profesorado- significa ser conscientes de la innovación que representan en todos esos campos. En general, diremos que se trata de una innovación cultural profunda y de largo alcance.

¿Desde qué enfoque debemos posicionarnos los educadores a la hora de incorporar las TIC en la enseñanza?

Creo que con una actitud positiva, vigilante e inteligente. Las TIC han venido para quedarse, pero son instrumentos maleables, que se pueden reconfigurar a condición de que los usemos consciente y creativamente. De eso se trata.
¿De qué modo inciden 0 deberían considerarse las redes sociales en el contexto educativo?

Un aula es una microrred social. Si la ampliamos vía TIC estaremos aprovechando un enorme potencial de nuestra actual sociedad. La perspectiva del trabajo colaborativo en red es positiva e inevitable, al mismo tiempo.

¿Qué ocurre con los artefactos típicos de la alfabetización como el libro? ¿Es posible repensarlos? ¿De qué modo?

Es necesario transformarlos. Creo que el libro interactivo digital en red será la base del futuro del sistema educativo.

¿De qué manera acompaña la TV educativo-cultural este proceso?

Depende de los países. Pero en general creo que la futura televisión educativa se declinará en Internet.

¿Cuáles nuevas perspectivas teóricas en educación son las indicadas para pensar estas nuevas alfabetizaciones, nuevos modos de conocer y aprender?

Se trata de un cambio global. Me parece que será una suma del la perspectiva social en la educación (Dewey), el cognitivismo (Piaget), el enfoque de la semiótica de la cultura y los estudios culturales (desde Peirce y Greimas hasta los estudios culturales, pasando por Lotman y Bajtín), el aprendizaje colaborativo apoyado en ordenadores, la teoría de la comunicación, etc. Y todo ello dentro de nuevas metodologías pedagógicas: enfoque competencial, aprendizaje colaborativo y exploratorio, trabajo por proyectos, solución de problemas, etcétera. 


\section{Hacia comunidades de aprendizaje}

Los usos de las redes sociales consolidan otro paradigma comunicacional. Pérez Tornero (2012) señala que en este proceso de alfabetización estamos frente a un cambio de paradigma: de los medios de comunicación de masas hacia los medios digitales o de comunicación multimedia. En la comunicación de masas «la audiencia se caracteriza por una relación unidireccional entre emisor y receptor y por la desconexión de sus miembros unos de otros: un patrón de uno a muchos». En el contexto de los medios digitales o de la comunicación multimedia el eje está puesto en una comunidad: es un patrón de muchos a muchos.

Afirma Pérez Tornero:

La pedagogía de la instrucción y la lectura crítica, que sigue teniendo en sí misma una importancia decisiva, abre paso - sobre todo en el terreno de los nuevos medios- a la pedagogía de la creación y de la participación (...) se trata de pasar de modelos teóricos que han acompañado el desarrollo de los medios de masas, a los modelos adaptados y ajustados al nuevo contexto de la interacción y de la comunicación digital (2005).

\section{Nuevas alfabetizaciones y nuevas competencias}

Entre los principales desafíos que enfrenta el ámbito educativo pueden mencionarse:

- Cómo integrar las tecnologías al aprendizaje y la enseñanza de las diferentes disciplinas o espacios curriculares y en distintos tramos de formación.

- Cómo propiciar instancias de trabajo creativo con las tecnologías, que permitan producir, comunicar, expresar, construir y no sólo «manejar las herramientas informáticas» 0 «leer críticamente los medios/las tecnologías»

- Tener presente en el diseño de la currícula los modos de alentar estas nuevas competencias digitales. 
Las nuevas destrezas requeridas están relacionadas con:

- Conocimientos operativos básicos relacionados con ordenadores y las pantallas;

- Competencias psicocognitivas vinculadas al lenguaje informático o digital;

- Competencia mediática interactiva con medios audiovisuales, digitales, trabajo en red y colaborativo;

- Competencias sociocomunicativas relacionadas con los modos de organizar vínculos y comunicarse en el ciberespacio.

En definitiva, habilidades que permitan una apropiación significativa de las tecnologías.

\section{Los nuevos libros de texto digitales}

Cabría pensarlos como

un servicio de contenidos educativos "abiertos» que permitan desarrollar las competencias personales e inviten a descubrir y a adquirir el conocimiento por sí mismos — los alumnoscon la ayuda o acompañamiento del profesor»; constituyendo "una herramienta flexible, abierta y «personalizable» en manos del profesor... para que éste pueda adaptarlo a las características de sus alumnos ( $\mathrm{Pi}, 2013)$.

\section{Televisión con contenido}

La televisión educativo-cultural es aquella que promueve identidades y valores culturales autónomos y diversos, con una intencionalidad transformadora que se vincula a la construcción de ciudadanía (una posible definición, a modo de propuesta), 


\section{Referencias bibliográficas}

Pérez Tornero, J. M. (2002). Crisis de educación, crisis de la comunicación. En Ágora Digital, 3.

(octubre de 2003). Educación en medios: perspectivas y estrategias. En Aguaded Gómez, J. I. (Coord.). Luces en el laberinto audiovisual = Luzes no labirinto audiovisual: Congreso Iberoamericano de Comunicación y Educación, Huelva.

(2004). Comprender la alfabetización digital. Promoting digital literacy Informe final EAC/76/03.

(2005a). Hacia un nuevo concepto de la educación en medios. Revista Comunicar 24. Barcelona. (2005b). Hacia un nuevo concepto de la educación en medios. Revista Comunicar 24. Barcelona. - (2013). La nueva competencia mediática en un contexto mediático. Material de lectura del Máster Internacional en Comunicación y Educación. Gabinete de Comunicación y Educación. Barcelona: Universitat Autònoma de Barcelona.

Pérez Tornero, J. M. y Varis, T. (2012). Alfabetización mediática y nuevo humanismo. Barcelona: Editorial UOC.
Wilson, C. (2012). Alfabetización mediática e informacional: proyecciones didácticas. Revista Comunicar XX (39). Barcelona.

Area, M. y Pessoa, T. (2012). De lo solido a lo líquido: las nuevas alfabetizaciones ante los cambios culturales de la Web 2. 0. Revista Comunicar XI X(38).

Duart, J. M. y Sangrà, A. (Eds.) (2000). Aprender en la virtualidad. Barcelona: Gedisa.

Pi, M. (2013). Unidad didáctica El libro de texto digital y los nuevos formatos para la edu-comunicación. Material de lectura del Máster internacional de Comunicación y Educación. Gabinete de Comunicación y Educación. Barcelona: Universitat Autònoma de Barcelona.

Flores Vivar, Jesús Miguel (2000): «Nuevos modelos de comunicación, perfiles y tendencias en las redes sociales». Revista Comunicar XVII, 33, v. Barcelona. Sloep, P. y Berlan G. A. (2011). Redes de aprendizaje, aprendizaje en red. Revista Comunicar XI X(37). Barcelona. 


\section{Acerca del entrevistado}

José Manuel Pérez Tornero es catedrático de Periodismo y doctor en Comunicación de la Universidad Autónoma de Barcelona; Doctor Honoris Causa por la Universidad de Aix-Marsella. Posee una amplia experiencia en el campo de la Comunicación y la Educación tanto en televisión como en multimedia en trabajos de asesoría y docencia. Desde 1994 dirige el Gabinete de Comunicación y Educación de la UAB. Se desempeña como vicepresidente de AITED (Asociación Internacional de Televisiones Educativas y de Descubrimiento) desde 1999. Es experto y consultor de la UNESCO y la Unión Europea en materia de servicio público de televisión y de alfabetización digital y mediática Además ha publicado numerosas obras en torno a la Comunicación y la Educación. Dirige el Master Internacional de Comunicación y Educación (Universitat Autònoma de Barcelona - UAB-). Estudia, investiga, experimenta y escribe sobre comunicación, educación y cultura mediática. Se ocupa especialmente de la relación entre comunicación, educación y ciudadanía, y de las políticas públicas relativas a estos temas. En sus estudios combina un enfoque teórico crítico — basado en la semiótica y el análisis de los discursos sociales - con proyectos de investigación y desarrollo $(I+D+I)$, prestando especial atención a las políticas de promoción de la alfabetización mediática, del servicio público audiovisual y de la cooperación en materia de TIC y medios de comunicación. 
